\title{
THE CONSTITUTIONAL AND LEGAL PROBLEMS OF APPLYING THE NATIONAL LAW OF RUSSIA IN THE PRACTICE OF THE EUROPEAN COURT OF HUMAN RIGHTS
}

\author{
Aleksey V. Ushakov \\ PProsecutor's Office of Voroshilovsky District of Volgograd; \\ Volgograd State University, Volgograd, Russian Federation \\ Sergey A. Gordeychik \\ Volgograd Regional Court, Volgograd, Russian Federation
}

\begin{abstract}
Introduction: the article is devoted to the identification of the constitutional and legal problems associated with applying the national legislation of the Russian Federation in adjudicating disputes in the inter-state body for the protection of human rights and freedoms. For this purpose the author studies the statistical data on the citizens " appeals to the European Court of Human Rights and the practice of protecting the violated rights. With the help of the methods of scientific knowledge, primarily the method of system analysis of the judicial and regulatory acts, the author comes to the need to improve this process. Results: the author indicates that there are contentious issues in adjudicating the citizens' appeals in inter-state body for the protection of the rights and freedoms of the individual.

Conclusions: according to the author, the implementation of the Constitutional Court of the Russian Federation of its powers to interpret the Constitution of the Russian Federation will provide the additional guarantees to the citizens when the European Court of Human Rights handles their claims.
\end{abstract}

Key words: the European Court of Human Rights, the Constitutional Court of the Russian Federation, interstate body, legal reasoning, remedy.

Citation. Ushakov A.V., Gordeychik S.A. The Constitutional and Legal Problems of Applying the National Law of Russia in the Practice of the European Court of Human Rights. Legal Concept, 2018, vol. 17, no. 4, pp. 148-153.

\section{КОНСТИТУЦИОННО-ПРАВОВЫЕ ПРОБЛЕМЫ ПРИМЕНЕНИЯ НАЦИОНАЛЬНОГО ПРАВА РОССИИ В ПРАКТИКЕ ЕВРОПЕЙСКОГО СУДА ПО ПРАВАМ ЧЕЛОВЕКА}

\author{
Алексей Викторович Ушаков \\ Прокуратура Ворошиловского района г. Волгограда; \\ Волгоградский государственный университет, г. Волгоград, Российская Федерация
}




\section{Сергей Алексеевич Гордейчик}

Волгоградский областной суд, г. Волгоград, Российская Федерация

Введение: статья посвящена выявлению конституционно-правовых проблем, связанных с применением национального законодательства РФ при рассмотрении споров в межгосударственном органе по защите прав и свобод человека. С это целью изучаются статистические сведения об обращении граждан в Европейский Суд по правам человека и практику защиты нарушенных прав. С помощью методов научного познания, в первую очередь системного анализа судебных и нормативно-правовых актов, доказывается необходимость совершенствования этого процесса. Результаты: в ходе исследования выявлено наличие спорных вопросов при рассмотрении обращений граждан в межгосударственном органе по защите прав и свобод человека. Выводы: реализация Конституционным Судом РФ своих полномочий по толкованию Конституции РФ предоставит дополнительные гарантии гражданам при рассмотрении жалоб в Европейском Суде по правам человека.

Ключевые слова: Европейский Суд по правам человека, Конституционный Суд РФ, межгосударственный орган, правовая позиция, защита права.

Цитирование. Ушаков А. В., Гордейчик С. А. Конституционно-правовые проблемы применения национального права России в практике Европейского Суда по правам человека // Legal Concept = Правовая парадигма. -2018. - Т. 17, № 4. - C. 148-153. - DOI: https://doi.org/10.15688/lc.jvolsu.2018.4.21

\section{Введение}

Граждане России согласно ч. 3 ст. 46 Конституции РФ вправе в соответствии с международными договорами Российской Федерации обращаться в межгосударственные органы по защите прав и свобод человека, если исчерпаны все имеющиеся внутригосударственные средства правовой защиты.

Конституция РФ предоставила гражданам возможность обращения в международные правозащитные органы, в том числе и судебные, для защиты своего нарушенного права. Так, ратификация Российской Федерацией Европейской конвенции по правам человека позволяет всем лицам, находящимся под ее юрисдикцией, обратиться в Европейский Суд по правам человека (далее ЕСПЧ), если они считают, что их права нарушены.

\section{Нормативно-правовое регулирование права на обращение в межгосударственные органы}

Европейская Конвенция о защите прав человека и основных свобод провозгласила основные права человека, а также предусмотрела механизм их защиты. Согласно ст. 6 Конвенции каждый гражданин в случае спора о его правах и обязанностях или при предъявлении ему любого уголовного обвинения имеет право на справедливое публичное разбирательство дела в разумный срок независимым и беспристрастным судом, созданным на основании закона [3]. По результатам рассмотрения дела судебные решения объявляются публично, однако средства массовой информации и посторонние граждане могут не допускаться на судебные заседания в течение всего процесса или его части по соображениям морали, общественного порядка или национальной безопасности в демократическом обществе. Кроме того, если этого требуют интересы несовершеннолетних, либо частной жизни граждан, либо в другой мере - при наличии особых обстоятельств, когда открытое и публичное рассмотрение дела нарушало бы интересы правосудия.

При достаточно обширной судебной практике рассмотрения обращений граждан неизбежно стоит вопрос об исполнении решений ЕСПЧ, имеющих обязательную силу для государств-участников Конвенции. Эта задача осуществляется ЕСПЧ путем рассмотрения и разрешения конкретных дел, принятых судом к производству на основании индивидуальных жалоб, направленных физическим лицом, группой лиц или общественной организацией. Допустима также подача жалобы на нарушение государством, членом Совета Европы, Конвенции со стороны дру- 


\section{МЕЖДУНАРОДНОЕ ПРАВО И СРАВНИТЕЛЬНОЕ ПРАВОВЕДЕНИЕ}

гого государства. Ратификация Конвенции и признание юрисдикции ЕСПЧ значит и то, что деятельность всех российских органов государственной власти, в том числе судебных, их решения и используемые процедуры, а также решения органов законодательной власти не должны противоречить требованиям Конвенции. Более того, в силу конституционных норм (ч. 4 ст. 15), Конвенция образует составную часть российской правовой системы [2]. Вместе с тем практика конституционного судопроизводства в России свидетельствует об имеющихся проблемах в применении конвенциального и национального права и возникающих спорах, связанных с исполнением решений ЕСПЧ.

Статистические данные состояния рассмотрения обращений российских граждан в ЕСПЧ представлены в таблице.

Приведенная статистика показывает, что активность российских граждан при использовании своего права на защиту межгосударственными средствами путем направления обращений в ЕСПЧ остается стабильно высокой на протяжении длительного времени. При этом следует отметить, что ЕСПЧ не является высшей судебной инстанцией по отношению к судебной системе государства-участника Конвенции. При выявлении незаконного или нарушающего права граждан судебного решения он не может его отменить, не дает указаний государственному органу, принявшему это решение, не осуществляет контроль за национальным законодательством, а также за судебной практикой, и не имеет право давать распоряжения о необходимости принятия мер, имеющих юридические последствия.

\section{Практика ЕСПЧ по рассмотрению жалоб граждан о защите своего нарушенного права}

Судом рассматриваются только конкретные, индивидуальные жалобы и обращения с целью установить, имели ли место нарушения требований Конвенции. Следует отметить, что суд вправе присудить «справедливое удовлетворение претензии» в виде финансовой компенсации материального ущерба и морального вреда, а также возмещение выигравшей стороне всех издержек и расходов, понесенных в связи с обращением в суд [6].

Неисполнение решения в соответствии с уставом Совета Европы может привести к приостановлению членства государства в его составе, а впоследствии - к исключению из него. В случае, если государство указывает, что без изменения законодательства или судебной практики рассмотренная ЕСПЧ ситуация может возникнуть вновь, государством принимаются меры к внесению изменений в действующее законодательство либо осуществляется корректировка судебной практики [8].

Так, в постановлении от 15 января 2009 г. по делу «Бурдов против России» (№ 2) ЕСПЧ, опираясь на ранее выработанные им позиции, пришел к выводу, что ст. 46 Конвенции о защите прав человека и основных свобод возлагает на государство-ответчика правовое обязательство не только произвести заинтересованным лицам выплаты, присужденные в качестве справедливой компенсации за признанное постановлением ЕСПЧ нарушение, но и принять меры общего характера, а если необходимо и индивидуальные меры, с тем, чтобы в национальной правовой практике положить конец

\section{Данные статистики по состоянию рассмотрения обращений граждан РФ в ЕСПЧ}

\begin{tabular}{|c|c|c|c|}
\hline Период & $\begin{array}{c}\text { Жалобы, поступившие } \\
\text { для рассмотрения }\end{array}$ & $\begin{array}{c}\text { Жалобы, объявленные неприемлемыми } \\
\text { либо исключенные из числа } \\
\text { подлежащих рассмотрению }\end{array}$ & $\begin{array}{c}\text { Жалобы, } \\
\text { по которым вынесены } \\
\text { постановления }\end{array}$ \\
\hline 2011 & 12422 & 12223 & 199 \\
\hline 2012 & 22358 & 22142 & 216 \\
\hline 2013 & 24102 & 23845 & 257 \\
\hline 2014 & 15792 & 15574 & 218 \\
\hline 2015 & 6712 & 6552 & 160 \\
\hline 2016 & 7010 & 6365 & 645 \\
\hline
\end{tabular}

Примечание. Составлено по: [8]. 
этому нарушению и устранить, насколько возможно, его последствия, причем такие меры должны предприниматься и в отношении других лиц, оказавшихся в положении заявителя, право которого ЕСПЧ признал нарушенным [5].

Таким образом, при рассмотрении ЕСПЧ жалобы обратившегося лица в своем решении он не только обязывает государство произвести выплаты заинтересованным лицам в виде компенсации за нарушенное право, но и принять меры, направленные на корректировку национального законодательства и практики рассмотрения дел указанной категории [1].

Вместе с тем нужно отметить и случаи, когда ЕСПЧ вмешивался в компетенцию национальной судебной системы без учета ранее вынесенных решений и изложенных в них правовых позиций. Такая ситуация сложилась в 2010 г., когда по делу «Маркин против России» ЕСПЧ было вынесено решение, в котором констатировано, что запрет военнослужащему мужчине на получение отпуска по уходу за ребенком является дискриминацией по половому признаку. В марте 2012 г. Большая палата ЕСПЧ в постановлении по жалобе Маркина установила нарушение Россией ст. 8 (право на частную жизнь) и 14 (запрет дискриминации) Европейской конвенции о защите прав человека и основных свобод [8].

Вместе с тем при рассмотрении дела ЕСПЧ не было учтено, что эту ситуацию уже ранее рассматривал Конституционный Суд РФ, который установил, что заниматься своими детьми гражданин может только в случае ухода с военной службы. То есть, рассматривая правовой спор, возникший при реализации социального права военнослужащего на отпуск по уходу за ребенком до 3-х лет, Конституционный Суд РФ руководствовался интересами государства, а именно - необходимостью обеспечения защиты безопасности и его обороны.

При этом, формулируя свою правовую позицию, Конституционный Суд РФ исходил из содержания ч. 3 ст. 55 Конституции РФ, которая прямо предусматривает возможность ограничения федеральным законом прав и свобод человека и гражданина в случаях необходимости обеспечения обороны страны и безопасности государств [2].

Решение ЕСПЧ, поставившее под сомнение правовую позицию Конституционного Су- да РФ, вызвало резкое неприятие в Российской Федерации. Впоследствии указанное дело было пересмотрено, и ЕСПЧ постановил, что отпуск по уходу за ребенком возможен только для военнослужащих-мужчин, занимающих должность вспомогательного состава [8].

Разрешая возникшую правовую коллизию по вопросу применения сформулированных судебными инстанциями правовых позиций, Конституционный Суд РФ подтвердил свое право на толкование Основного закона РФ. 6 декабря 2013 г. Конституционный Суд РФ постановил, что только он может разрешить вопрос о применимости законодательных норм, которые препятствуют исполнению постановления ЕСПЧ, но не были ранее признаны неконституционными.

Изменениями в Федеральный конституционный закон «О Конституционном Суде Российской Федерации» 04.06.2014 № 9-ФК3 ст. 101 федерального конституционного закона дополнена ч. 2 следующего содержания: «Суд при пересмотре в случаях, установленных процессуальным законодательством, дела в связи с принятием межгосударственным органом по защите прав и свобод человека решения, в котором констатируется нарушение в Российской Федерации прав и свобод человека при применении закона или его отдельных положений, придя к выводу, что вопрос о возможности применения соответствующего закона может быть решен только после подтверждения его соответствия Конституции РФ, обращается с запросом в Конституционный Суд РФ о проверке конституционности этого закона» [4].

В качестве иллюстрации, наряду с делом «Маркин против России», приведу ссылки на Постановления ЕСПЧ от 20.09.2011 по делу «ОАО “НК “Юкос" против России», а также Постановление ЕСПЧ от 04.07.2013 по делу «Анчугов и Гладков против РФ», которыми на государственные органы Российской Федерации возложено выполнение ряд действий по внесению изменений в федеральное законодательство [6].

Таким образом, в случае принятия соответствующего постановления ЕСПЧ, которое является основанием для пересмотра гражданского дела по новым обстоятельствам, приведенными изменениями предусмотрена про- 


\section{МЕЖДУНАРОДНОЕ ПРАВО И СРАВНИТЕЛЬНОЕ ПРАВОВЕДЕНИЕ}

цедура проверки на конституционность примененного в ходе судебного разбирательства федерального закона. Так, суд при пересмотре дела в соответствии с постановлением ЕСПЧ в рамках действующего российского законодательства может прийти к выводу о невозможности применения правовой нормы по причине ее несоответствия Конституции РФ. Поскольку Европейская конвенция о защите прав человека и основных свобод по существу признает те же ценности, что и Конституция РФ, такой вывод ориентирует к необходимости обращения с запросом для проверки конституционности нормы, затронутой постановлением ЕСПЧ.

\section{Выводы}

Конституция РФ предоставила гражданам России возможность обращения в международные правозащитные органы, в том числе и судебные, для защиты своего нарушенного права. Ратификация Российской Федерацией Европейской конвенции по правам человека позволяет всем лицам, находящимся под юрисдикцией, обратиться в ЕСПЧ если они считают, что их права являются нарушенными. При таких обстоятельствах деятельность ЕСПЧ является дополнительной гарантией защиты прав и свобод человека и гражданина в международных правозащитных организациях и не должна препятствовать в необходимых случаях обращениям за защитой в Конституционный Суд РФ Таким образом, решения ЕСПЧ, соответствующие духу и содержанию Конституции РФ, исходя из закрепленных в Конвенции прав и свобод и общепризнанных норм международного права, а также включая право на доступ к суду, являются составной частью российской правовой системы.

Российская Федерация, являясь суверенным государством, вправе разрабатывать и применять правовые механизмы, направленные на защиту конституционных ценностей и действующего Основного закона.

\section{СПИСОК ЛИТЕРАТУРЫ}

1. Гончаров, А. И. Регулирование нормативов банковской деятельности в ЕС / А. И. Гончаров,
О. П. Казаченок // Вестник Волгоградского государственного университета. Серия 5. Юриспруденция. -2015 . - № 2. - С. 159-163.

2. Конституция Российской Федерации: принята всенародным голосованием 12 декабря 1993 г. : (с учетом поправок, внесенных ФКЗ Российской Федерации о поправках к Конституции Российской Федерации от 30 декабря 2008 г. № 6-ФКЗ, от 30 декабря 2008 г. № 7- ФКЗ) // Собрание законодательства Российской Федерации. - 2009. - № 4. - Ст. 445.

3. Конвенция о защите прав человека и основных свобод ETS № 005 (Рим, 4 ноября 1950 г.) // Собрание законодательства Российской Федерации. - 2001. - № 2. - Ст. 163.

4. О внесении изменений в Федеральный конституционный закон «О Конституционном Суде Российской Федерации» : Федеральный конституционный закон № 9-ФКЗ от 04.06.2014 // Российская газета. - 2014. - № 127. - С. 17.

5. Постановление ЕСПЧ от 15.01.2009 «Дело “Бурдов против Российской Федерации”» (№ 2) (жалоба № 33509/04). - Электрон. текстовые дан. - Режим доступа: http://www.echr.ru/documents (дата обращения: 19.09.2013).

6. Право Европейского союза : учебник и практикум для бакалавриата и магистратуры / под ред. А. Х. Абашидзе, А. О. Иншаковой. - М. : Юрайт, 2016. $-482 \mathrm{c}$.

7. Современные проблемы организации публичной власти : монография / С. А. Авакьян [и др.] ; рук. авт. кол. и отв. ред. С. А. Авакьян. - М. : Юстицинформ, 2014. - 596 с.

8. Сайт Европейского Суда по правам человека. - Электрон. текстовые дан. - Режим доступа: http:/ /www.echr.coe.int/Documents/CP_Russia_RUS.pdf (дата обращения: 15.01.2018).

\section{REFERENCES}

1. Goncharov A.I., Kazachenok O.P. Regulirovanie normativov bankovskoy deyatelnosti v ES [Regulation of Banking Standards in the EU]. Vestnik Volgogradskogo gosudarstvennogo universiteta. Seriya 5, Yurisprudentsiya [Science Journal of Volgograd State University. Jurisprudence], 2015, no. 2, pp. 159-163.

2. Konstitutsiya Rossiyskoy Federatsii: prinyata vsenarodnym golosovaniem 12 dekabrya 1993 g.: (s uchetom popravok, vnesennykh FKZ Rossiyskoy Federatsii o popravkakh k Konstitutsii Rossiyskoy Federatsii ot 30 dekabrya 2008 g. № 6-FKZ, ot 30 dekabrya 2008 g. № 7- FKZ) [The Constitution of the Russian Federation: Adopted by Popular Vote on December 12, 1993 (as Amended by the Federal Law of the Russian Federation on Amendments to the 
Constitution of the Russian Federation of December 30, 2008 No. 6-FKZ, of December 30, 2008 No. 7-FKZ)]. Sobranie zakonodatelstva Rossiyskoy Federatsii [Collected Legislation of the Russian Federation], 2009, no. 4 , art. 445.

3. Konventsiya o zashchite prav cheloveka i osnovnykh svobod ETS № 005 (Rim, 4 noyabrya 1950 g.) [Convention for the Protection of Human Rights and Fundamental Freedoms ETS No. 005 (Rome, November 4, 1950)]. Sobranie zakonodatelstva Rossiyskoy Federatsii [Collected Legislation of the Russian Federation], 2001, no. 2, art. 163.

4. O vnesenii izmeneniy v Federalnyy konstitutsionnyy zakon «O Konstitutsionnom Sude Rossiyskoy Federatsii»: Federalnyy konstitutsionnyy zakon № 9-FKZ ot 04.06.2014 [On Amendments to the Federal Constitutional Law 'On the Constitutional Court of the Russian Federation': Federal Constitutional Law No. 9-FKZ of 6 April 2014]. Rossiyskaya gazeta, 2014, no. 127, p. 17.
5. Postanovlenie ESPCh ot 15.01.2009 «Delo “Burdov protiv Rossiyskoy Federatsii”" (№ 2) (zhaloba № 33509/04) [Resolution of the ECHR of January 15, 2009 'The Case of Burdov vs. the Russian Federation' (No. 2) (Complaint No. 33509/04)]. URL: http:// www.echr.ru/documents (accessed 19 September 2013).

6. Abashidze A.Kh., Inshakova A.O., eds. Pravo Evropeyskogo soyuza: uchebnik i praktikum dlya bakalavriata i magistratury [The Law of the European Union: Textbook and Practical Guide for Bachelor and Master Students]. Moscow, Yurayt Publ., 2016. 482 p.

7. Avakyan S.A., et al. (eds.) Sovremennye problemy organizatsii publichnoy vlasti: monografiya [Modern Problems of Public Authority Organization: Monograph]. Moscow, Yustitsinform Publ., 2014. 596 p.

8. Sayt Evropeyskogo Suda po pravam cheloveka [Website of the European Court of Human Rights]. URL: http://www.echr.coe.int/Documents/ CP_Russia_RUS.pdf(accessed 15 January 2018).

\section{Information about the Authors}

Aleksey V. Ushakov, Prosecutor of Voroshilovsky District of Volgograd, Senior Lecturer, Volgograd State University, Prosp. Universitetsky, 100, 400062 Volgograd, Russian Federation, ushakov_alex@mail.ru, https://orcid.org/0000-0003-0282-7602

Sergey A. Gordeychik, Candidate of Sciences (Jurisprudence), Judge of the Volgograd Regional Court, Prosp. Lenina, 8, 400005 Volgograd, Russian Federation, pensero1@yandex.ru, https:/orcid.org/ 0000-0003-0282-7602

\section{Информация об авторах}

Алексей Викторович Ушаков, прокурор Ворошиловского района г. Волгограда, старший преподаватель, Волгоградский государственный университет, просп. Университетский, 100, 400062 г. Волгоград, Российская Федерация, ushakov_alex@mail.ru, https://orcid.org/0000-0003-0282-7602

Сергей Алексеевич Гордейчик, кандидат юридических наук, судья Волгоградского областного суда, просп. Ленина, 8, 400005 г. Волгоград, Российская Федераци, pensero1@yandex.ru, https://orcid.org/0000-0003-0282-7602 